\title{
Recent progress in R\&D on tungsten alloys for divertor structural and plasma facing materials
}

S. Wurster ${ }^{a, *}$, N. Baluc ${ }^{b}$, M. Battabyal ${ }^{b}$, T. Crosbyc ${ }^{c}$ J. Du ${ }^{d}$, C. García-Rosales ${ }^{e}$, A. Hasegawa ${ }^{\dagger}$, A. Hoffmann', A. Kimura ${ }^{h}$, H. Kurishita', R.J. Kurtz', H.Lia,k ${ }^{\mathrm{a}}$, S. Noh', J.Reiser $^{m}$, J. Riesch ${ }^{d}$, M. Rieth ${ }^{m}$, W. Setyawan', M. Walter ${ }^{m}$, J.-H. You ${ }^{d}$, R. Pippan ${ }^{a}$

a Erich Schmid Institute of Materials Science, Leoben, Austria \& Association EURATOMÖAW

${ }^{\mathrm{b}}$ Ecole Polytechnique Fédérale de Lausanne (EPFL), Villigen PSI, Switzerland c University of California, Mechanical and Aerospace Engineering Department, Los Angeles, CA, USA

d Max-Planck-Institut für Plasmaphysik, Garching, Germany

e Centro de Estudios e Investigaciones Técnicas de Gipuzkoa (CEIT), San Sebastián, Spain

${ }^{\dagger}$ Department of Quantum Science \& Energy Engineering, Faculty of Engineering,

Tohoku University, Japan g Plansee Metall GmbH, Reutte, Austria

${ }^{\mathrm{h}}$ Institute of Advanced Energy, Kyoto University, Japan

' International Research Center for Nuclear Material Science, Institute for Materials Research, Tohoku University, Japan

j Pacific Northwest National Laboratory, Richland, WA, USA

${ }^{k}$ Chair of Atomistic Modelling and Design of Materials, University of Leoben, Leoben, Austria

I Japan Atomic Energy Agency

' Karlsruhe Institute of Technology, Karlsruhe, Germany

* corresponding author, Tel:+43(0)3842-804-325, Fax:+43 (0) 3842804 116, Jahnstrasse 12, A-8700 Leoben, stefan.wurster@unileoben.ac.at 


\begin{abstract}
Tungsten materials are candidates for plasma-facing components for the International Thermonuclear Experimental Reactor and the DEMOnstration power plant because of their superior thermophysical properties. Because these materials are not common structural materials like steels, knowledge and strategies to improve the properties are still under development. These strategies discussed here, include new alloying approaches and microstructural stabilization by oxide dispersion strengthened as well as TiC stabilized tungsten based materials. The fracture behavior is improved by using tungsten laminated and tungsten wire reinforced materials. Material development is accompanied by neutron irradiation campaigns. Self-passivation, which is essential in case of loss-of-coolant accidents for plasma facing materials, can be achieved by certain amounts of chromium and titanium. Furthermore, modeling and computer simulation on the influence of alloying elements and heat loading and helium bombardment will be presented.
\end{abstract}

\title{
1. Introduction
}

W-based materials feature several advantageous properties for fusion application, e.g., high melting point, good thermal conductivity, high creep resistance, good high-temperature strength and low vapor pressure. W has a high resistance against sputtering and low tritium retention in fusion environments [1]. The calculated radioactivity of $W$ as a first wall material after shutdown of an anticipated fusion reactor after receiving a certain neutron fluence is better when compared to other high melting elements such as $\mathrm{Nb}$ and $\mathrm{Mo}$; however, it is worse compared to potential alloying elements such as $\mathrm{Ti}$ and $\mathrm{V}$ [2]. However, there are drawbacks: low oxidation resistance, low ductility at room temperature (RT) and high ductileto-brittle transition temperature (DBTT). Furthermore, some of its properties are sensitive to irradiation.

Several activities have started in Europe [3], Japan [4], the USA and China [5]. Research is directed towards manufacturing of new materials based on alloying, microstructure stabilizing and composite formation involving improved processing steps. In addition to experimental analyses, work also focuses on computational treatment of open questions, supporting the development of better tungsten materials. Assuming the availability of an ideal material that is ready to use, there remain the questions of inherent safety, the joining of tungsten to steel and the influence of radiation damage. These are topics of increasing interest when the material comes to application. 
Several approaches to increase ductility and fracture toughness and to decrease the DBTT will be discussed in Section 2. These approaches include alloying of W with Ti, V, Ta and Re. An explanation for the rhenium-ductilizing effect is given, based on quantum mechanical calculations. Ductility can also be enhanced by using ultra-fine grained (UFG) and nanocrystalline materials. However, these microstructures have to be stabilized to withstand recrystallization at high temperatures, which can be realized by oxide dispersion strengthened (ODS) (Section 2.2) or additions of TiC (Section 2.3). Two approaches presented in Sections 2.4 and 2.5. are very promising for an improved fracture behavior of $\mathrm{W}$-based components. The first one relies on a brazed laminate made of a stack of $\mathrm{W}$ foils and $\mathrm{AgCu}$ brazing filler. A notable shift of DBTT to lower temperatures was found for W laminates in Charpy tests. The second approach bases on the increased energy dissipation within W wire-reinforced W composites during crack propagation.

To handle the above-mentioned problem of low oxidation resistance, research is directed towards self-passivating $\mathrm{W}$ alloys containing $\mathrm{Cr}$, Si and Ti. Production, microstructure and thermomechanical properties of these materials are described in Section 3. ODS steels and $\mathrm{W}$ are desired as structural and plasma-facing materials of the first wall (FW) and divertor components in the DEMOnstration power plant (DEMO) [6,7]. Depending on the exact design and cooling strategy (e.g. water cooled, He-cooled finger design, He-cooled laminate pipe concept) that will be used for future fusion reactors, the temperatures structural and armor materials will be exposed to, vary significantly. Section 4 outlines the formation and compares the properties of two different joining processes between ODS steels and W. Recent campaigns on neutron irradiation effects on several W-based materials are described in Section 5. The last section focuses on modeling of heat loading and He bombardment and on ab initio calculations of the influence of several transition metals on grain boundary (GB) decohesion. 


\section{Enhancing ductility and toughness}

\subsection{Tungsten alloying}

Alloying $\mathrm{W}$ with $\mathrm{Re}$ is known to lower the Peierls stress, $\sigma_{\mathrm{P}}$, and to clearly increase the toughness at high $\mathrm{Re}$ concentrations close to the limit of solubility $[8,9]$. Even for small additions of $\mathrm{Re}$, the solid solution softening process [10] is active and leads to ductilization and toughening [11]. The influence of alloying can be explained using density-functional theory (DFT). The characteristic features of plastic deformation of bcc metals arise from peculiarities of non-planar $1 / 2<111>$ screw dislocations. Computer simulations on the dislocation-core structure and energy have already been performed for $\alpha$-iron $[12,13]$. Based on DFT, the influences of Ta and Re alloying in W on the core structure (Fig. 1), $\sigma_{\mathrm{P}}$, and slip plane of $1 / 2<111>$ screw dislocations are investigated [8,14]. Alloying with $\mathrm{Re}$ is found to change the core symmetry, decrease the $\sigma_{\mathrm{P}}$, and increase the number of slip planes, which result in the ductilizing effect. However, this is not the case for W-Ta alloys. It is concluded that the increase of $d$-electrons alters the atomic bonding, leading to enhanced dislocation mobility and improved plastic deformation. From this point of view, Os and Ir are interesting alloying elements. Dislocation kink formation [15] is another important issue in completely understanding plastic deformation. Unfortunately, Re, Os and Ir are rare elements. For fusion applications, $\mathrm{Re}$ additions have to be restricted to fulfill low activation requirements [16] and to avoid the formation of brittle phases due to significant transmutation of $W$ into $R e$. Therefore, the question is whether there are other applicable elements with a ductilizing effect on $\mathrm{W}$.

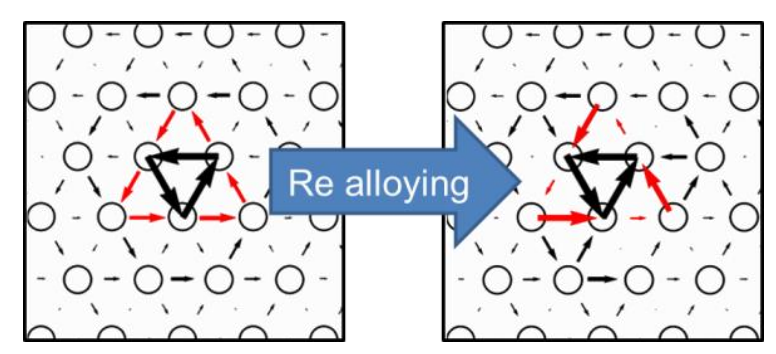

Fig 1: Transition of dislocation-core symmetry introduced by Re alloying. Empty circles are atoms projected on the (111) surface; displacements along the [111] direction are represented by arrows connecting neighboring atoms. 
Only a few metals have significant solubility in $\mathrm{W}$ at $\mathrm{RT}$. Of those, even fewer do not form brittle intermetallic compounds. Only $\mathrm{Ta}, \mathrm{V}, \mathrm{Nb}$ and Mo form solid solutes in the complete fraction range. Besides these, a few, e.g., Ti and Re exhibit a limited solubility. Their applicability is restricted to fractions of about $12 \%$ and $27 \%$, respectively, due to the formation of intermetallic $\sigma$ - and X-phases $[17,18]$. Since Nb and Mo transmute to very longlived radioactive isotopes, they cannot be used for fusion applications; this leaves $\mathrm{Ta}, \mathrm{V}$, and $\mathrm{Ti}$ as possible candidates. However, alloying with $\mathrm{Ta}$ and $\mathrm{V}$ does not improve DBTT or the Charpy energy (Fig. 2); moreover, the fracture toughness of W-Ta alloys decreases with increasing Ta content [19]. Recent studies with $\mathrm{Ti}$, which should be verified using a different fabrication route, have not led to promising results [20,21]. Furthermore, DFT investigations on $\mathrm{V}$ and $\mathrm{Ti}$ alloying were carried out with the same strategy as for $\mathrm{Re}$ and $\mathrm{Ta}$, but did not reveal significant changes on the dislocation-core symmetry. Hence, from this point of view, no ductilizing effect is expected from $V$ alloying. However, Ti changes the core structure, but in a different way than Re does; the effect on $\sigma_{P}$ still has to be investigated.

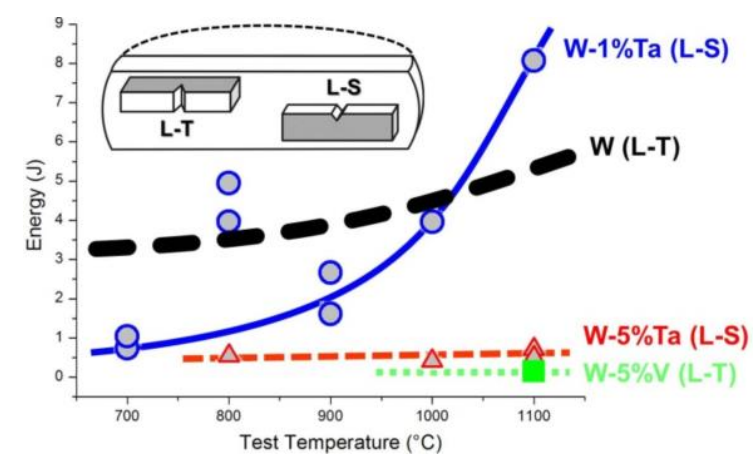

Fig. 2: Charpy test results of pure W, W-Ta, and W-V alloys. The specimens were fabricated out of round blanks that were forged to a height reduction of $80 \%$. The chosen orientations are sketched.

Hence, it seems unlikely that the ductility of $W$ would be improved on a technical scale by formation of substitution solid solutions other than by Re. A lesson that was learned is that the alignment of the microstructure is crucial for good properties. A plate-like microstructure is favorable for good toughness in two out of three directions. Methods to stabilize advantageous microstructures will be discussed in the next subsections. 


\subsection{Oxide dispersion strengthened / stabilized materials}

W-based materials for structural applications are developed based on the idea that alloys and especially nano-grained materials should be more ductile than pure $\mathrm{W}$ and standard grain-sized materials [22]. Furthermore, nano-grained materials and dispersion strengthened materials should be more radiation resistant than pure $\mathrm{W}$ and standard grain-sized materials, as the numerous grain boundaries and interfaces between matrix and particles are expected to act as sinks for the irradiation-induced defects [23]. In addition, the particles are expected to stabilize the grain boundaries in nano-grained materials upon thermal annealing and/or irradiation.

The W materials produced by standard powder metallurgy (PM) methods include pure $\mathrm{W}$ and W-Ti, W-V and W-Ta alloys, reinforced or not with $\mathrm{Y}_{2} \mathrm{O}_{3}, \mathrm{La}_{2} \mathrm{O}_{3}$ or TiC particles. For instance, $\mathrm{W}-(0.3-1.0-2.0) \mathrm{Y}, \mathrm{W}-(0.3-1.0-2.0) \mathrm{Y}_{2} \mathrm{O}_{3}$, and $\mathrm{W}-(0.3-0.9-1.7) \mathrm{TiC}$ (in wt\%) were produced at the laboratory scale by Mechanical Alloying (MA) and Hot Isostatic Pressing (HIPping) [24]. Grain sizes range between 20 and $500 \mathrm{~nm}$; the grains contain a high density (5.4-6.9 x $10^{22} \mathrm{~m}^{-3}$ ) of small $\mathrm{Y}_{2} \mathrm{O}_{3}$ or TiC particles, with sizes between 1 and $50 \mathrm{~nm}$. For $\mathrm{W}-\mathrm{Y}$ materials, all the $\mathrm{Y}$ transformed into $\mathrm{Y}_{2} \mathrm{O}_{3}$ during $\mathrm{MA}$ is due to $\sim 1 \mathrm{wt} \%$ of $\mathrm{O}$ within the milled powders. This is beneficial for reducing the excess $O$ content in the materials. All materials contain a residual porosity of a few percents, which is typical for HIPped material, and they exhibit high strength and a promising radiation resistance. In spite of the small grains, they show no ductility and have poor fracture properties at low to moderate temperatures. For instance, the DBTT of W-2Y typically was between $1373 \mathrm{~K}$ and $1473 \mathrm{~K}$.

However, a more promising $\mathrm{W}-2 \mathrm{Y}_{2} \mathrm{O}_{3}$ material was recently produced by sintering and hot forging in collaboration with the Plansee company (Austria) [25]. The relative density of the ingot is $99.3 \%$. The mean grain size is $\sim 1 \mu \mathrm{m} ; \mathrm{Y}_{2} \mathrm{O}_{3}$ particles with sizes between 300 and 900 $\mathrm{nm}$ are present. The Berkovich hardness is $4.9 \mathrm{GPa}$, being slightly higher than the typical Vickers microhardness of pure $\mathrm{W}$ of about 3.4 GPa. Three-point bending (3PB) tests showed that the material is brittle at $298 \mathrm{~K}$ and ductile at $673 \mathrm{~K}$ and above. The bending stresses at fracture range from $\sim 1.3 \mathrm{GPa}$ at $298 \mathrm{~K}$ down to $\sim 580 \mathrm{MPa}$ at $1273 \mathrm{~K}$ [19]. This was confirmed by tensile tests that showed that the material is fully ductile in the investigated temperature range of $673 \mathrm{~K}-1273 \mathrm{~K}$; the total elongation is between $4 \%$ and $10 \%$ (Fig. 3 ). It is important to notice that again the microstructural design, here from hot forging, is at least as important as the ODS effect. 
Preliminary dual-beam ion irradiation experiments in the Joint Accelerators for Nanosciences and Nuclear Simulation (JANNuS) facility in Saclay, (France) with $24 \mathrm{MeV} \mathrm{Fe}^{8+}$ ions and $2 \mathrm{MeV} \mathrm{He}$ ions, at $573 \mathrm{~K}$ and $773 \mathrm{~K}$ up to about $5 \mathrm{dpa}$ (in steels) and $75 \mathrm{appm} \mathrm{He} / \mathrm{dpa}$, showed the presence of $\mathrm{He}$ bubbles and a slight radiation hardening characterized by a Berkovich hardness of about 5.5 GPa. An increase in hardness might be detrimental as the ductility of the material decreases after irradiation.

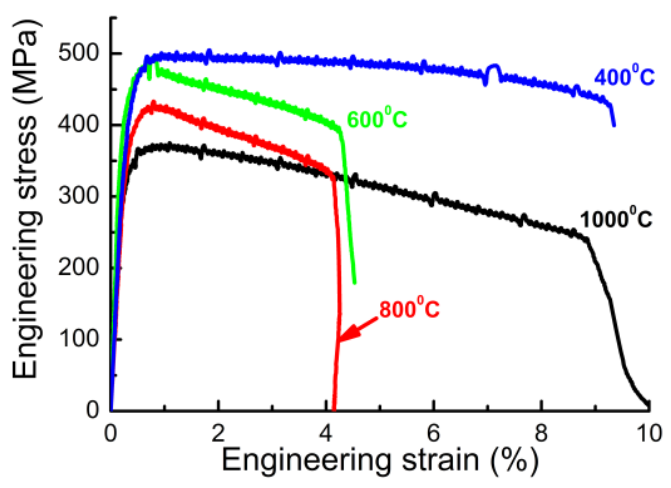

Fig. 3: Temperature-dependent tensile stress-strain curves of sintered and hot-forged W$2 \mathrm{Y}_{2} \mathrm{O}_{3}$.

\subsection{Recent progress in nanostructured W-TiC materials}

Radiation and recrystallization embrittlement are the major concerns about W-materials to be used as plasma facing materials. A promising solution to these problems is to develop nanostructures that can offer much-improved mechanical properties in the recrystallized state. UFG, densified W-(0.25-1.5)\%TiC compacts with recrystallized, equiaxed grain sizes of 50-200 nm and fine TiC dispersoids at grain boundaries (GBs) were developed by PM methods utilizing MA and HIPping $[26,27]$. TiC was selected because of its high melting point $(\sim 3400 \mathrm{~K})$ and a self-adjustment capability of the lattice constant by forming a solid solution with $\mathrm{W}$ and non-stoichiometric $\mathrm{TiC}_{\mathrm{x}}$. UFG W-0.5TiC compacts exhibit negligibly small hardening by neutron irradiation [27], no blistering nor flaking by $3 \mathrm{MeV} \mathrm{He}$ irradiation [28], and superplastic deformation by GB sliding above 1673K [26,29-31].

There are some issues of concern for UFG W-TiC: (1) Even in the non-irradiated state, the UFG compacts did not exhibit any ductility below $823 \mathrm{~K}$, mainly due to weak GBs of random orientations, extremely high yield strength (5 6 GPa) and the presence of residual pores (relative density: 98 99\%). (2) Irradiation with $1 \mathrm{keV} \mathrm{H}_{3}$ containing $\sim 0.8 \% \mathrm{C}$ did not cause 
significant blistering but produced small holes on the surface, probably by ejection of grains [32]. (3) The thermal conductivity of W-0.5TiC is considerably lower than that of pure W. The thermal conductivity of W and UFG W-TiC become closer at high temperatures [33,34]. (4) Thermal shock loading under ELM (edge localized modes) conditions as they will happen within the International Thermonuclear Experimental Reactor (ITER) caused cracking in network-like patterns with a maximum depth of $170 \mu \mathrm{m}$ [34]

A new microstructural modification method was developed to strengthen the GBs in the recrystallized state, adjust the grain size and remove the residual pores. The method is based on significant activation of GB sliding by superplastic deformation that is attributed to the UFG structures and thus defined as "superplasticity-based microstructural modification (SPMM)" $[4,16,35]$. GB sliding essentially leaves the structure recrystallized, equiaxed and fine grained and significantly enhances GB precipitation of $\mathrm{TiC}$ or segregation of the $\mathrm{TiC}$ constituents and strengthens the weak random GBs. The optimized SPMM process at $1923 \mathrm{~K}$ was applied to UFG W-1.1TiC with the highest superplastic elongation among W-(0.251.5) TiC and successfully converted it to a toughened, fine-grained and recrystallized (TFGR) compact that exhibits very high fracture strength up to about 4.4 GPa and appreciable bend ductility even at RT $[4,36]$, despite a fully recrystallized structure. The resultant microstructure also possesses a large number of effective sinks of mostly random GBs and TiC dispersoids.

The DBTT, defined as the no-ductility temperature, of TFGR W-1.1TiC decreases with decreasing O-impurity content and lies below RT when the $\mathrm{O}$ content is below 400 wppm. This is most probably due to a susceptible nature of the dispersoids (precipitates) to the $O$ impurity, which increases the tendency of brittle $\mathrm{W}_{2} \mathrm{C}$ phase formation with increasing $\mathrm{O}$ content. It is noted that O-controlled TFGR W-1.1TiC is highly tolerant to thermal shock loading [34] and thermal fatigue [37] as well as low-energy, high-flux, high-fluence ion bombardment at $573 \mathrm{~K}$ in pure deuterium (D) and D/He mixture plasmas (no holes) [38]. Thermal shock loadings under ITER/ELM conditions do not cause any cracking or surface roughening in TFGR $\mathrm{W}-1.1 \mathrm{TiC}$ with a low $\mathrm{O}$ content [34], although the thermal conductivity of TFGR W-1.1TiC was almost the same as that of UFG W-0.5TiC [34]. Given the recent progress in research on $\mathrm{W}-\mathrm{TiC}$, it is now necessary to assess the alloys under conditions closer to the anticipated ambient conditions in ITER. Neutron irradiation tests on TFGR W$1.1 \mathrm{TiC}$ are in progress and an effective processing technology is under development to meet the suitable sample dimension requirement for the ITER divertor application. 


\subsection{W laminates made of $W$ foils}

[35]lt is well known that body-centered cubic (bcc) metals can be ductilized by prior cold work [39]. Furthermore, it was shown for ODS $W$ that recrystallization and fracture toughness increase with increasing degree of deformation [40]. It can be concluded that DBTT decreases with increasing degree of deformation [41]. This led to a new idea, which consists of synthesizing a $\mathrm{W}$ laminate made of several layers of $\mathrm{W}$ foils.

During fabrication, the foil was exposed to a high degree of deformation, and therefore it is ductile. It can be bent plastically even at RT. The tensile properties at RT also show ductile behavior; however, they are anisotropic and depend strongly on the rolling direction. By assembling several layers of ductile $\mathrm{W}$ foils followed by a subsequent joining process it is possible to expand the ductile properties of foils to bulk material. The success of the procedure depends strongly on the joining technology and joining parameters as well as the material used for the interlayer bonding. In this work, a W laminate was synthesized from 20 layers of $\mathrm{W}$ foils, which were joined at $1073 \mathrm{~K}$ with 19 layers of eutectic $\mathrm{AgCu}$ brazing filler (Fig. 4, inset). Each layer had a thickness of $0.1 \mathrm{~mm}$ and the $\mathrm{W}$ foil was oriented in rolling direction $\left(0^{\circ}\right)$. This $\mathrm{W}$ laminate was characterized by Charpy impact tests; more details on this testing procedure can be found elsewhere [42-44].

The results of Charpy impact properties of the laminate are compared to pure $\mathrm{W}$ plate material. Fig. 4 shows that the samples made of $W$ foil can dissipate energy at much lower temperatures than samples made of pure $\mathrm{W}$ (as-received). Even at RT, the W-laminate absorbs nearly $2 \mathrm{~J}$. The maximum energy dissipation of the $\mathrm{W}$ laminate is at $573 \mathrm{~K}$ and is about $10 \mathrm{~J}$, which is higher than that of pure $\mathrm{W}(8 \mathrm{~J})$. These excellent results show that the ductile properties of $W$ foils were successfully expanded to bulk W material. Fig. 4 also illustrates the assessment of annealed W. Samples made of annealed plate material $(1 \mathrm{~h} /$ $2273 \mathrm{~K}$ ) cannot dissipate energy even at high temperature $(1273 \mathrm{~K})$. The $\mathrm{W}$ laminate made of annealed $\mathrm{W}$ foils $(1 \mathrm{~h} / 2073 \mathrm{~K}$ ), shows a DBTT at $773 \mathrm{~K}$ and is nearly as good as asreceived plate material. Nevertheless, an important future task will be to stabilize the foils' microstructure. Because the microstructure of as-received foils is completely different from that of the annealed state, there might be different reasons for the ductility of $W$ foils. One reason might be the 'foil effect' which is the dislocation annihilation on the free surface respectively on the interface between the hard $\mathrm{W}$ and the soft brazing filler. 


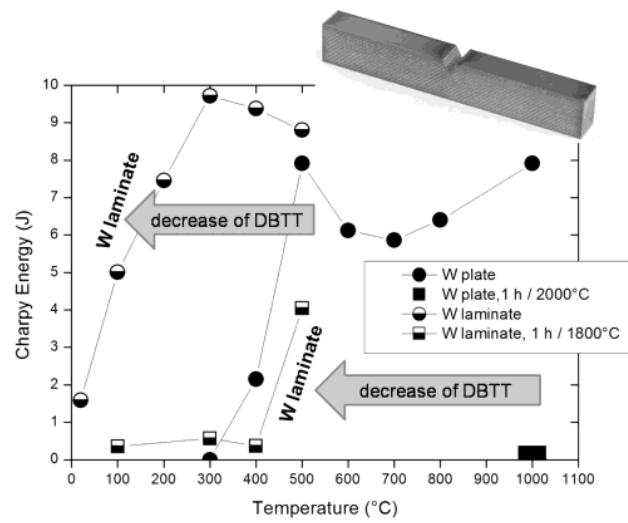

Fig. 4: Results of Charpy impact tests for W laminates compared to W plate material in asreceived and annealed condition. The inset shows a Charpy test sample made of 20 layers of W foil $\left(0.1 \mathrm{~mm}, 0^{\circ}\right)$ and 19 layers of $\mathrm{AgCu}$ brazing filler $(0.1 \mathrm{~mm})$.

\subsection{Tungsten-wire-reinforced tungsten composites with pseudo-toughness}

Recently, You et al. proposed a novel toughening concept based on W-wire reinforcement and demonstrated the potential benefit of corresponding $W$ composites [45]. This toughening method utilizes both inherent toughness of $W$ wires and pseudo-toughness by energy absorption at the engineered wire/matrix interfaces [46-48]. The mechanism of pseudotoughness is as follows. Under critical load, a matrix crack is initiated and propagates. When the crack meets the array of reinforcing wires standing perpendicular to the crack front, it deflects along the interfaces if a specific fracture mechanical condition is fulfilled. The stored strain energy dissipates by interfacial debonding and subsequent frictional sliding without catastrophic failure of the whole component. To this end, one needs relatively weak interfaces. Since this mechanism is a purely mechanics-based process not needing plasticity, it is supposed to function even under neutron irradiation conditions. Upon incremental extension of the primary crack, the strong wires collectively bridge the main crack flanks, suppressing dynamic fracture. The total amount of absorbed energy is the measure of apparent toughness.

Here, the fracture mechanical properties of the interface are the key factor. To achieve the maximal global toughness, the fracture toughness of the interface has to be optimized by coating. To this end, You et al. fabricated a number of single- and multi-filament model composite specimens using various kinds of interface coatings and identified the interfacial parameters such as shear strength and debonding energy by means of fiber push-out tests and inverse fitting to relevant theoretical models $[49,50]$. All determined parameters satisfied 
the criterion of crack deflection. The mechanism of controlled crack deflection at interfaces was also visually demonstrated by in situ 3PB tests using scanning electron microscopy (SEM) (Fig. 5) and miniaturized tension tests using in situ synchrotron microtomography. All fracture tests exhibited substantial energy dissipation caused by interfacial debonding processes and the capability of reliable wire bridging. In addition, even recrystallized and thus embrittled composite specimens showed similar debonding and bridging behavior. For fabrication of multifilament bulk composites, a new processing route was developed based on a gas-phase infiltration technique. Residual porosity could be reduced below $5 \%$. The wire-reinforced composites offer a positive prospect for making a breakthrough towards a tough material [45].

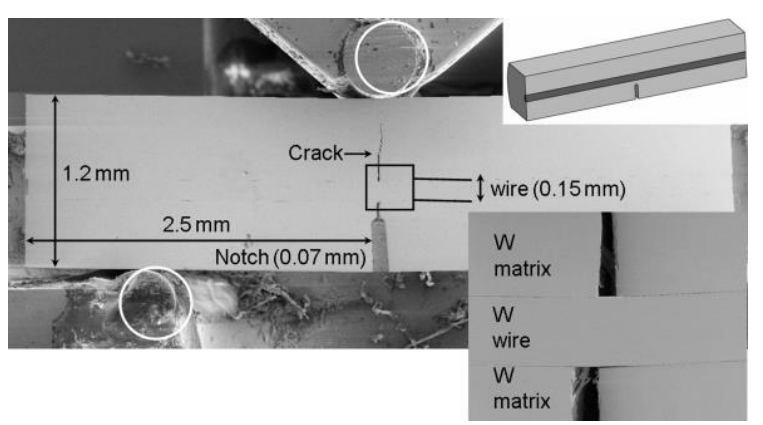

Fig. 5: Scanning electron micrograph made during an in situ 3PB fracture experiment. The detail view shows the propagating crack bypassing the wire. 


\section{Self-passivating tungsten alloys}

The use of $\mathrm{W}$ represents an important safety concern in case of a loss-of-coolant accident with simultaneous air ingress into the reactor vessel. Temperatures up to $1473 \mathrm{~K}$ can be achieved in the in-vessel components within a few weeks due to the decay heat [51], which would lead to fast oxidation with the release of volatile, activated $W$ oxides [52]. The linear oxidation rate of $\mathrm{W}$ at $1273 \mathrm{~K}$ is about $1.4 \times 10^{-2} \mathrm{mg} \mathrm{cm}^{-2} \mathrm{~s}^{-1}$ [53], and for $\sim 1000 \mathrm{~m}^{2}$ of DEMO FW this could mean a release of $0.5 \mathrm{t}$ of $\mathrm{W}$ oxides per hour. A possible method for avoiding this important safety issue is the addition of oxide-forming alloying elements leading to the growth of a self-passivating layer at high temperature in the presence of oxygen. During normal operation, the surface will consist of $\mathrm{W}$, owing to preferential sputtering of alloying elements.

In previous work, different $\mathrm{W}$ alloys have been manufactured via magnetron sputtering (physical vapor deposition, PVD) [53,54], demonstrating that thin films of WCr10Si10 (in wt.\%) exhibit excellent self-passivating behavior when exposed to air at temperatures up to $1273 \mathrm{~K}$. Since the PVD route is not industrially relevant, because thicknesses of several $\mathrm{mm}$ are required for the FW armor, WCr10Si10 bulk alloys have been manufactured by PM (MA + HIP) obtaining an almost $100 \%$ dense material [55]. The microstructure consists mainly of $(\mathrm{W}, \mathrm{Cr})_{5} \mathrm{Si}_{3}$ mixed crystal, pure $\mathrm{W}$ grains and isolated $\mathrm{SiO}_{2}$ grains. In addition, an ultrafine ODS-like phase, inhibiting grain growth, is detected. The oxidation rate is lower than the one of corresponding thin films at $873 \mathrm{~K}$, though higher at $1273 \mathrm{~K}$ [58]. The brittleness of the main phase $(\mathrm{W}, \mathrm{Cr})_{5} \mathrm{Si}_{3}$ has a detrimental effect on its workability, which has motivated the development of Si-free alloys. Based on the results of [56], introducing W-Cr-Ti thin-film alloys with even lower oxidation rates, WCr12Ti2.5 bulk alloys have been manufactured by MA + HIP, obtaining again 100\% density [57]. The microstructure (Fig. 6) consists mainly of two bcc phases $(\alpha \mathrm{W}, \mathrm{Cr})$ and $(\alpha \mathrm{Cr}, \mathrm{W})$ together with some pure Ti grains. The thermal conductivity of this alloy is close to $50 \mathrm{~W} / \mathrm{mK}$ at $873 \mathrm{~K}$, which is enough for the intended application, and is significantly higher than that of WCr10Si10 [57]. Further details on manufacturing and mechanical properties of these alloys can be found in [57]. 


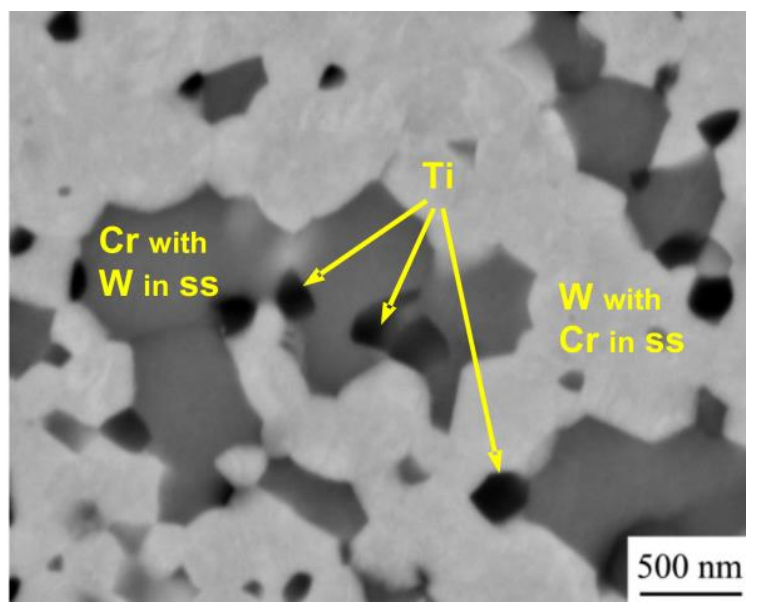

Fig. 6: Scanning electron micrograph using backscattered electrons of a WCr12Ti2.5 sample after HIP [55,57]. Cr is in solid solution (SS) in W and vice versa.

\section{Joining W plate with ODS steel}

ODS steels show excellent elevated-temperature strength, corrosion resistance and radiation resistance [59-61]. Thus, joining of ODS steel with $W$ is an essential issue for the construction of divertors; however, the mismatch of coefficients of thermal expansion (CTE) $\left(\mathrm{W}=4.3 \times 10^{-6} \mathrm{~K}^{-1}\right.$, a-steel $\left.=10.5 \times 10^{-6} \mathrm{~K}^{-1}\right)$ complicates joining. One possibility would be to increase the CTE of W-based materials, e.g. by production of composites including $V[19,62]$. Diffusion bonding processes were chosen for this work on pure W and ODS steel, because it is an attractive technique to obtain W-layered ODS-steel components with excellent interfacial strength.

Two types of processes, liquid phase diffusion bonding (LPDB) and solid-state diffusion bonding (SSDB), and their joint microstructure and strength were investigated [63]. Highchromium ODS ferritic steel, $\mathrm{Fe}-19 \mathrm{Cr}-0.3 \mathrm{Ti}-0.3 \mathrm{Y}_{2} \mathrm{O}_{3}$ was prepared for joining. Material for brazing was a sheet of the iron-based amorphous alloy, ALLOY 2605S-2 (Fe-3B-5Si) with a thickness of $25 \mu \mathrm{m}$. The melting point of the insert material was $1423 \mathrm{~K}$; B and Si act as melting point depressants. LPDB and SSDB were performed in vacuum of about $10^{-5} \mathrm{~Pa}$ in a hot press for various joining periods. In each case, the LPDB and SSDB temperature was $1513 \mathrm{~K}$, slightly higher than the melting point of the insert material.

The microstructural examination revealed that both LPDB and SSDB were successful; no voids were visible in the bonding interfaces. The LPDB joint was composed of four regions: 1) pure $W, 2$ ) an interdiffusion layer, 3) insert material and 4) ODS steel. The interface of $W$ 
with insert material contains an interdiffusion layer of $3 \mu \mathrm{m}$ thickness composed of $\mathrm{W}, \mathrm{Fe}, \mathrm{Cr}$ and $\mathrm{B}$ and originating from diffusion processes. The amorphous insert material probably melted during bonding and its melting-point depressants diffused into the ODS steel and resultantly crystallized with a thickness of $15 \mu \mathrm{m}$. In the SSDB joint, an interdiffusion layer with a thickness of $5 \mu \mathrm{m}$, which consists of $\mathrm{W}, \mathrm{Fe}, \mathrm{Cr}$ and $\mathrm{C}$, was observed at the interface of W with ODS steel. It appears that a diffusion-affected zone (DAZ) exists in the ODS steel close to the interface, in which $\mathrm{W}$ diffused along grain boundaries of the ODS steel.

Nano-hardness distributions in the cross sections of both joint regions are shown in Fig. 7. The hardness in the area of residual insert material decreased to $3.3 \mathrm{GPa}$ because of the large grains of the residual insert material. There is no effect of $W$ diffused in the DAZ region on the hardness. On the contrary, the hardness distribution in the SSDB joint region has a sharp peak at the W/ODS-steel interface. An interdiffusion layer, composed of W, Fe, Cr and $\mathrm{C}$, explains the high hardness.

For evaluating the shear strength at the joint region, miniaturized torsion tests were performed at RT. Both joint regions show little plastic strain. However, the shear strength of the LPDB joint region is as high as $300 \mathrm{MPa}$ and higher than that of the SSDB joint region (150-250 MPa). The fracture modes of both joints are clearly different; the fracture surface of the LPDB joint has a conical shape on the ODS steel side, while the SSDB joint has a rather flat fracture surface with radial exfoliation. This suggests that the LPDB joint needed higher fracture energy under torsional shear stress than the SSDB joint, and this fact corresponds well to the evaluated shear strength.

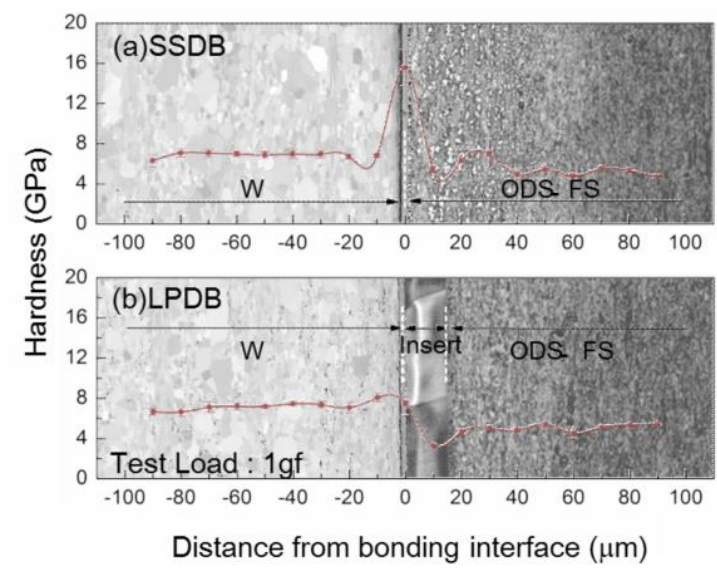

Fig. 7: Hardness distributions on the cross-sectional area of W and ODS-steel joints: (a) SSDB, (b) LPDB [63]. 


\section{Neutron irradiation of tungsten}

Neutron irradiation data on microstructural development in $\mathrm{W}$ and $\mathrm{W}$-Re alloys were obtained from the JOYO reactor, the Japan Materials Testing Reactor (JMTR) and the High Flux Isotope Reactor (HFIR) irradiation experiments at $773 \mathrm{~K}$ to $1073 \mathrm{~K}$. The calculated irradiation damage levels were in the range of $0.15-1.5 \mathrm{dpa}$ with a displacement threshold energy of 90 $\mathrm{eV}$ and the following scenario of damage structure development in pure $\mathrm{W}$ at around $773 \mathrm{~K}$ to $1073 \mathrm{~K}$ under fusion reactor conditions is considered. For low damage levels, void and dislocation loop formation occurs. With increased damage level, voids become major damage structures and void lattices form at higher temperatures. Small amounts of $\operatorname{Re}(3-$ $5 \%)$ suppressed the void formation, and irradiation-induced precipitates were observed. For the $\mathrm{W}$-26Re alloy, precipitates became the major irradiation structures. The irradiation hardening increased with the formation of the precipitates [64-67]. In the case of HFIR irradiation, the microstructure and electrical resistivity of irradiated pure $\mathrm{W}$ were dramatically different from JOYO-irradiated W, because larger amounts of Re were generated by nuclear transmutation of W to Re, which is due to HFIR's higher flux of thermal neutrons, leading to a transmutation rate 10 times larger than in JOYO [68]. Furthermore, neutron irradiation behavior of La-doped W, K-doped W and UFG W-TiC were examined in JOYO and JMTR using disk-type specimens (804-1073 K, 0.15-0.47 dpa) for transmission electron microscopy. After neutron irradiation, electrical resistivity - measured at RT - increased about 10 to $20 \%$. The effects of the La and $\mathrm{K}$ doping on the electrical resistivity were small compared with the UFG-W alloys. For $0.42 \mathrm{dpa}$ at $1029 \mathrm{~K}$, the major irradiation damage consists of small voids for all materials; additionally, dislocation loops were observed for UFG W-TiC [69]. 


\section{Modeling and computer simulation}

\subsection{Modeling of heat load and helium bombardment damage}

The presence of defects inside the material (e.g. He bubbles [70], voids, self-interstitial atoms) is responsible for the discrepancy between the actual and theoretical strengths of the material and the degradation of these properties. The goal of this work was to develop multiscale models to study the effects of transient plasma heat loads and helium bombardment on the thermo-mechanical damage in $\mathrm{W}$ [71].

A multiphysics computational model has been developed within a finite-element framework to study the synergistic effects of transient plasma events and the existence of He bubbles on the thermomechanical damage of $\mathrm{W}$. The model consisted of a transient heat conduction analysis, coupled with a quasi-static elastoplastic structural mechanics analysis, together with a GB-damage mode that includes contact-cohesive elements for GB sliding and fracture.

The thermomechanical model indicates that transient heating of $\mathrm{W}$ that already contains $\mathrm{He}$ bubbles will result in the evolution of subsurface residual stresses, material swelling, GB sliding, and sub-surface mechanical damage, leading to the degradation of thermophysical properties. The effects of different heat fluxes were simulated, and the results showed surface damage by the formation of primary and secondary intergranular microcracks. The microcracks' sizes and depths vary with the heat load profile. The developed model provided satisfactory results that are in general agreement with the experimental observations. When the surface was subjected to a heat flux of $1 \times 10^{4} \mathrm{MW} / \mathrm{m}^{2}$ for $0.1 \mathrm{~ms}$, surface deformation and roughening due to plasticity were observed (Fig. 8). Grain ejection, occurring at the same heat flux, resulted from the complete separation of GBs closer to the surface. 


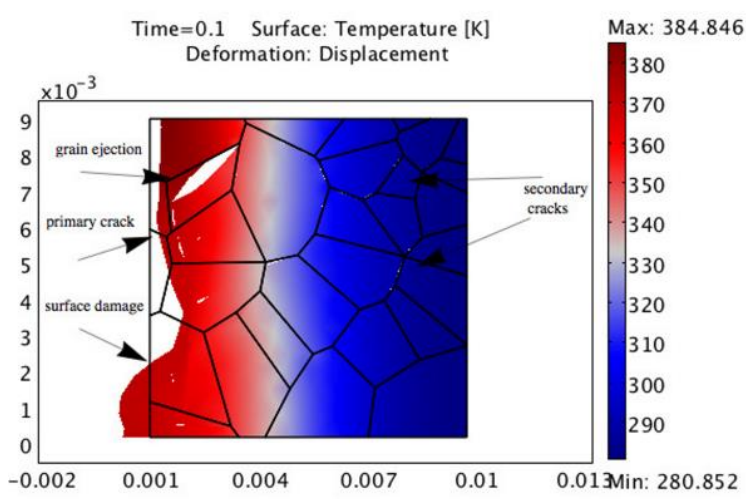

Fig. 8: Temperature distribution in $\mathrm{K}$ and damage due to differential thermal expansion/contraction and crack formation. The surface was subjected to a heat flux of $1 \mathrm{x}$ $10^{4} \mathrm{MW} / \mathrm{m}^{2}$ for $0.1 \mathrm{~ms}$ are indicated. Axes in $\mathrm{mm}$.

\subsection{Ab initio study of transition metals on tungsten grain boundary cohesion}

It was understood early that brittle fracture in $\mathrm{W}$ mainly occurs along GBs. Subsequently it was shown that by reducing the level of impurities (e.g., N, O, P, S) segregating at the GBs, more ductile materials were obtained. Recent experiments demonstrated that in $\mathrm{W}$ alloys produced currently, the purity is sufficiently high [72]. Given the myriad of factors affecting the characteristics of real materials, computational approaches are valuable tools to guide experimental research. In subsection 2.1. the outstanding properties of W-Re alloys were already discussed. Furthermore, computational work predicted that Rh, Ir, Os, and Ru might also reduce the Peierls barrier [73]. Setyawan et al. started a series of computational studies on the effects of transition metals on the cohesion of W GBs [74]. As a representative model, a $\sum 27<110>\{525\}$ symmetrical tilt GB was selected.

The structure of the $\sum 27 \mathrm{~GB}$ was constructed from a general-twin configuration [75]. Initially, classical molecular dynamics (MD) simulations using an interatomic potential [76] were performed to scan for energetically low configurations. To find the ground state structure, the top half of the slab was shifted systematically along the basal dimensions and the atoms were allowed to move and relax. The ground state structure from MD simulations was subsequently optimized, using an ab initio method, to get the final structure (Fig. 9a). VASP (Vienna Ab initio Simulation Package) software was used to perform the first principles calculations [77,78]. Accurate all-electron atomic potentials were modeled within the projector-augmented-wave pseudopotentials [79,80]. The Perdew - Burke - Erzernhof parametrizations were used for the electronic exchange-correlations energies [81]. ACONVASP utility software was used to build various $\{525\}$ slabs for VASP to determine the 
appropriate thickness [82]. It was found that 62 layers were necessary to avoid the interactions between the GB and the free surface.

Fig. 9b shows the cleavage energy of the $\Sigma 27$ GB upon substituting of $W$ atoms at different positions with $\mathrm{Ru}, \mathrm{Rh}, \mathrm{Re}$, Os, or Ir. The plotted energy represents the Griffith ideal cleavage energy with the fracture plane denoted by a dashed line in Fig. 9a. All elements strengthen the GB when they are present at position $A$ or $E$, but weaken the $G B$ when at $B, C$, or $D$. The calculated cleavage energy without impurities was $4160 \mathrm{~mJ} / \mathrm{m}^{2}$. The largest effect is observed for Os, which causes $\sim 6 \%$ increase in cleavage energy. To assess the net effect for each element, the formation energies at different GB sites were compared. It was found that the strengthening sites $\mathrm{A}$ and $\mathrm{E}$ also correspond to the most stable positions. In addition, the higher the cleavage energy, the more stable the GB site. To compare the stability across different transition metals, segregation energies were calculated. They were defined as the energy needed to swap an impurity atom at a bulk position with a $W$ atom at a GB site. The results show that for all GB positions, the larger the difference of the electronic valence of the impurity atom with respect to $W$, the more the element tends to segregate at the GB. This is consistent with the trend in the maximum solubility of the elements which is $25.7,6.3,5.7,4.3$ and 1.7 at\% for $\mathrm{Re}, \mathrm{Ru}, \mathrm{Os}, \mathrm{Rh}$, and Ir respectively.

On the one hand, a stable substitution at GB sites is needed in order to enhance the intergranular cohesion. On the other hand, strong GB segregation needs to be avoided so that enough alloying atoms are dissolved in the bulk to maintain the reduction of the Peierls stress. In particular, segregation at decohesion sites $B, C$, and D needs to be prevented. Considering these requirements, $\mathrm{Os}, \mathrm{Re}$, and $\mathrm{Ru}$ are particularly suited to improving the intrinsic ductility as well as enhancing interfacial cohesion. The improved GB cohesion by $\mathrm{Re}$ addition observed in this study partly explains the inherent increase of the recrystallization temperature of W-Re alloy. 

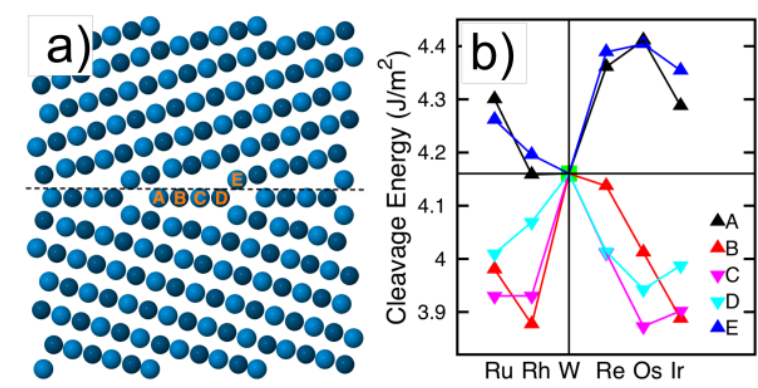

Fig. 9: a) Model structure of the $W \sum 27<110>\{525\}$ general twin $G B$ as viewed from the $<110>$ direction. The dashed line denotes the position of the GB cleavage plane. Different colors represent different coordinates along the $<110>$ direction. b) Cleavage energy as a function of substitutional elements at different positions.

Experimental data shows that the temperature dependence of the Charpy energy of $\mathrm{W}-1 \% \mathrm{Ta}$ and $\mathrm{W}-5 \%$ Ta differs significantly at high temperature regime (Figure 2). For the $\mathrm{W}-5 \% \mathrm{Ta}$, the value remains nearly constant, while for the $\mathrm{W}-1 \% \mathrm{Ta}$, the value rapidly increases for $\mathrm{T}>$ $1200 \mathrm{~K}$. In fact, at this regime, the Charpy energy of W-1\%Ta is larger than that of pure W. From the DFT calculation, Ta was found to strengthen the cohesion of the $\Sigma 27 \mathrm{~GB}$ when it resides at site $\mathrm{D}$. At this site, Ta is energetically most stable. At other sites, Ta reduces the cohesion. It is possible that for low concentrations of Ta and at high temperatures, thermal energy allows $\mathrm{Ta}$ to find its most stable site strengthening the cohesion that may explain the superior Charpy energy of W-1\%Ta compared to pure W. DFT calculations also revealed that lower-valence solutes ( $\mathrm{Hf}, \mathrm{Ta})$ and higher-valence solutes ( $\mathrm{Ru}, \mathrm{Re}, \mathrm{Os})$ strengthen the cohesion at different sites [74]. This suggests that ternary alloys employing a combination of lower- and higher-valence elements may perform better than binary alloys against intergranular fracture. 


\section{Summary}

Smart $\mathrm{W}$ materials have to be developed that can withstand the harsh environment in the divertor region. For improving mechanical properties, alloying with Re has proven by experiments and calculations to be advantageous; however, the application is inhibited due to the element's low availability. Other solid solution elements that dramatically improve the properties are not in sight. Material development has to rely on stabilizing beneficial microstructures by dispersoids. They help to keep a UFG microstructure, even at high temperatures, which is necessary because it maintains mechanical properties; furthermore, boundaries and interfaces act as sinks for irradiation-induced defects. Consequently, the next step is to use these improved materials, featuring a self-passivation layer on top for withstanding accidental air ingress, in a sophisticated configuration. This was shown for Wreinforced materials with $\mathrm{W}$ wires in crack arrester alignment and $\mathrm{W}$ laminate material that extends the excellent ductile properties of thin foils to bulk materials. When smart materials become available, they will have to be tested for joining and irradiation performances.

\section{Acknowledgement}

The work presented on this publication is partly funded by the European Commission, but does not necessarily represent its views or those of its agents. W.S. \& R.J.K. acknowledge U.S. Department of Energy (contract DE-AC06-76RLO-1830) and Pacific Northwest National Laboratory supercomputer (EMSL-45390). 


\section{References}

[1] Y. Ueda, K. Tobita, Y. Katoh, Journal of Nuclear Materials 313-316 (2003) 32.

[2] S. Cierjacks, Fusion Engineering and Design 13 (1990) 229.

[3] M. Rieth, S.L. Dudarev, S.M. Gonzalez De Vicente, J. Aktaa, T. Ahlgren, S. Antusch, D.E.J. Armstrong, M. Balden, N. Baluc, M.-F. Barthe, W.W. Basuki, M. Battabyal, C.S. Becquart, D. Blagoeva, H. Boldyryeva, J. Brinkmann, M. Celino, L. Ciupinski, J.B. Correia, A. De Backer, C. Domain, E. Gaganidze, C. García-Rosales, J. Gibson, M.R. Gilbert, S. Giusepponi, B. Gludovatz, H. Greuner, K. Heinola, T. Höschen, A. Hoffmann, N. Holstein, F. Koch, W. Krauss, H. Li, S. Lindig, J. Linke, C. Linsmeier, P. López-Ruiz, H. Maier, J. Matejicek, T.P. Mishra, M. Muhammed, A. Muñoz, M. Muzyk, K. Nordlund, D. Nguyen-Manh, J. Opschoor, N. Ordás, T. Palacios, G. Pintsuk, R. Pippan, J. Reiser, J. Riesch, S.G. Roberts, L. Romaner, M. Rosiński, M. Sanchez, W. Schulmeyer, H. Traxler, A. Ureña, J.G. Van Der Laan, L. Veleva, S. Wahlberg, M. Walter, T. Weber, T. Weitkamp, S. Wurster, M.A. Yar, J.H. You, A. Zivelonghi, Journal of Nuclear Materials 432 (2013) 482.

[4] Y. Ueda, H.T. Lee, N. Ohno, S. Kajita, A. Kimura, R. Kasada, T. Nagasaka, Y. Hatano, A. Hasegawa, H. Kurishita, Y. Oya, in:, Physica Scripta T, 2011.

[5] Q.-Z. Yan, X.-F. Zhang, Z.-J. Zhou, W.-P. Shen, Y.-C. Zhang, S.-M. Wang, L. Xu, C. Ge, Journal of Nuclear Materials

[6] R.J. Kurtz, A. Alamo, E. Lucon, Q. Huang, S. Jitsukawa, A. Kimura, R.L. Klueh, G.R. Odette, C. Petersen, M.A. Sokolov, P. Spätig, J.-W. Rensman, Journal of Nuclear Materials 386-388 (2009) 411.

[7] J. Reiser, P. Norajitra, R. Ruprecht, Fusion Engineering and Design 83 (2008) 1126.

[8] L. Romaner, C. Ambrosch-Draxl, R. Pippan, Physical Review Letters 104 (2010).

[9] S. Wurster, B. Gludovatz, R. Pippan, International Journal of Refractory Metals and Hard Materials 28 (2010) 692.

[10] E. Pink, R.J. Arsenault, Progress in Materials Science 24 (1980) 1.

[11] Y. Mutoh, K. Ichikawa, K. Nagata, M. Takeuchi, Journal of Materials Science 30 (1995) 770.

[12] L. Ventelon, F. Willaime, Philosophical Magazine 90 (2010) 1063.

[13] E. Clouet, L. Ventelon, F. Willaime, Physical Review Letters 102 (2009).

[14] H. Li, S. Wurster, C. Motz, L. Romaner, C. Ambrosch-Draxl, R. Pippan, Acta Materialia 60 (2012) 748.

[15] L. Ventelon, F. Willaime, P. Leyronnas, Journal of Nuclear Materials 386-388 (2009) 26.

[16] L. El-Guebaly, R. Kurtz, M. Rieth, H. Kurishita, A. Robinson, Aries Team, Fusion Science and Technology 60 (2011) 185. 
[17] T. Loewenhoff, A. Bürger, J. Linke, G. Pintsuk, A. Schmidt, L. Singheiser, C. Thomser, Physica Scripta T145 (2011) 014057.

[18] J.W. Coenen, V. Philipps, S. Brezinsek, G. Pintsuk, I. Uytdenhouwen, M. Wirtz, A. Kreter, K. Sugiyama, H. Kurishita, Y. Torikai, Y. Ueda, U. Samm, the TEXTOR-Team, Nuclear Fusion 51 (2011) 113020.

[19] S. Wurster, B. Gludovatz, A. Hoffmann, R. Pippan, Journal of Nuclear Materials 413 (2011) 166.

[20] M.V. Aguirre, A. Martín, J.Y. Pastor, J. Llorca, M.A. Monge, R. Pareja, Metallurgical and Materials Transactions A: Physical Metallurgy and Materials Science 40 (2009) 2283.

[21] M.V. Aguirre, A. Martín, J.Y. Pastor, J. Llorca, M.A. Monge, R. Pareja, Journal of Nuclear Materials 404 (2010) 203.

[22] M. Faleschini, H. Kreuzer, D. Kiener, R. Pippan, Journal of Nuclear Materials 367-370 A (2007) 800.

[23] S. Wurster, R. Pippan, Scripta Materialia 60 (2009) 1083.

[24] L. Veleva, Contribution to the production and characterization of W-Y, W-Y2O3 and WTiC materials for fusion reactors, Thesis EPFL no 4995, 2011.

[25] M. Battabyal, R. Schäublin, P. Spätig, N. Baluc, Materials Science and Engineering A 538 (2012) 53.

[26] H. Kurishita, S. Kobayashi, K. Nakai, H. Arakawa, S. Matsuo, T. Takida, K. Takebe, M. Kawai, in:, Physica Scripta T, 2007, p. 76-80.

[27] H. Kurishita, S. Kobayashi, K. Nakai, T. Ogawa, A. Hasegawa, K. Abe, H. Arakawa, S. Matsuo, T. Takida, K. Takebe, M. Kawai, N. Yoshida, Journal of Nuclear Materials 377 (2008) 34.

[28] T. Ogawa, A. Hasegawa, H. Kurishita, S. Nogami, Journal of Nuclear Science and Technology 46 (2009) 717.

[29] H. Kurishita, S. Matsuo, H. Arakawa, S. Kobayashi, K. Nakai, T. Takida, K. Takebe, M. Kawai, Materials Science and Engineering A 477 (2008) 162.

[30] S. Matsuo, H. Kurishita, H. Arakawa, T. Takida, M. Kato, Y. Yamamoto, K. Takebe, M. Kawai, N. Yoshida, Materials Science and Engineering A 492 (2008) 475.

[31] H. Kurishita, S. Matsuo, H. Arakawa, M. Narui, M. Yamazaki, T. Sakamoto, S. Kobayashi, K. Nakai, T. Takida, K. Takebe, M. Kawai, N. Yoshida, Journal of Nuclear Materials 386-388 (2009) 579.

[32] Y. Ueda, N. Ohno, S. Kajita, H. Kurishita, H. Iwakiri, K. Tokunaga, N. Yoshida, Fusion Science and Technology 52 (2007) 513.

[33] H. Kurishita, S. Matsuso, H. Arakawa, T. Hirai, J. Linke, M. Kawai, N. Yoshida, Advanced Materials Research 59 (2009). 
[34] G. Pintsuk, H. Kurishita, J. Linke, H. Arakawa, S. Matsuo, T. Sakamoto, S. Kobayashi, K. Nakai, in:, Physica Scripta T, 2011.

[35] M. Kawai, H. Kurishita, H. Kokawa, S. Watanabe, N. Sakaguchi, K. Kikuchi, S. Saito, T. Yoshiie, H. Iwase, T. Ito, S. Hashimoto, Y. Kaneko, M. Futakawa, S. Ishino, Journal of Nuclear Materials 431 (2012) 16.

[36] H. Kurishita, S. Matsuo, H. Arakawa, T. Sakamoto, S. Kobayashi, K. Nakai, T. Takida, M. Kato, M. Kawai, N. Yoshida, Journal of Nuclear Materials 398 (2010) 87.

[37]K. Tokunaga, H. Kurishita, H.Arakawa, S.Matsuo, T. Hotta, K. Araki, Y. Miyamoto, T. Fujiwara, K. Nakamura, T. Takida, M. Kato, A. Ikegaya, this proceeding.

[38] M. Miyamoto, D. Nishijima, Y. Ueda, R.P. Doerner, H. Kurishita, M.J. Baldwin, S. Morito, K. Ono, J. Hanna, Nuclear Fusion 49 (2009).

[39] P.B. Hirsch, S.G. Roberts, J. Samuels, Revue de Physique Appliquée 23 (1988) 409.

[40]I. Wesemann, P. Heel, W. Spielmann, A. Hoffmann, 17 Plansee Seminar (2009).

[41] E. Lassner, W.-D. Schubert, Tungsten - Properties, Chemistry, Technology of the Element, Alloys, and Chemical Compounds, Springer, Berlin, 1999.

[42] M. Rieth, A. Hoffmann, Fusion Science and Technology 56 (2009) 1018.

[43] M. Rieth, A. Hoffmann, Advanced Materials Research 59 (2009) 101.

[44] M. Rieth, A. Hoffmann, International Journal of Refractory Metals and Hard Materials 28 (2010) 679.

[45] J. Du, T. Höschen, M. Rasinski, S. Wurster, W. Grosinger, J.-H. You, Composites Science and Technology 70 (2010) 1482.

[46] A.G. Evans, Journal of the American Ceramic Society 73 (1990) 187.

[47] K.K. Chawla, Ceramic matrix composites, Chapman \& Hall, London, 1993.

[48] A.G. Evans, Acta Materialia 45 (1997) 23.

[49] J. Du, T. Höschen, M. Rasinski, J.-H. You, Materials Science and Engineering A 527 (2010) 1623.

[50] J. Du, T. Höschen, M. Rasinski, J.-H. You, Journal of Nuclear Materials 417 (2011) 472.

[51]D. Maisonnier et al., A Conceptual Study of Commercial Fusion Power Plants, Final Report, EFDA-RP-RE-5.0, 13 April 2005.

[52] N.P. Taylor, R. Pampin, Fusion Engineering and Design 81 (2006) 1333.

[53] F. Koch, H. Bolt, in:, Physica Scripta T, 2007, p. 100-105.

[54] F. Koch, S. Köppl, H. Bolt, Journal of Nuclear Materials 386-388 (2009) 572.

[55] P. López-Ruiz, N. Ordás, S. Lindig, F. Koch, I. Iturriza, C. García-Rosales, Physica Scripta T T145 (2011) 014018.

[56] F. Koch, J. Brinkmann, S. Lindig, T.P. Mishra, C. Linsmeier, Physica Scripta T145 (2011) 014019. 
[57]P. López-Ruiz, N. Ordás, I. Iturriza, F. Koch and C. García-Rosales, Powder metallurgical processing of self-passivating tungsten alloys for fusion first wall application, this proceedings, o. J.

[58] P. López-Ruiz, F. Koch, N. Ordás, S. Lindig, C. García-Rosales, Fusion Engineering and Design 86 (2011) 1719.

[59] A. Kimura, R. Kasada, N. Iwata, H. Kishimoto, C.H. Zhang, J. Isselin, P. Dou, J.H. Lee, N. Muthukumar, T. Okuda, M. Inoue, S. Ukai, S. Ohnuki, T. Fujisawa, T.F. Abe, Journal of Nuclear Materials 417 (2011) 176.

[60] H.S. Cho, H. Ohkubo, N. Iwata, A. Kimura, S. Ukai, M. Fujiwara, Fusion Engineering and Design 81 (2006) 1071.

[61] P. Dou, A. Kimura, T. Okuda, M. Inoue, S. Ukai, S. Ohnuki, T. Fujisawa, F. Abe, Acta Materialia 59 (2011) 992.

[62] J. Hohe, P. Gumbsch, Journal of Nuclear Materials 400 (2010) 218.

[63] S. Noh, R. Kasada, N. Oono, T. Nagasaka, A. Kimura, Materials Science Forum 654656 (2010) 2891.

[64] T. Tanno, A. Hasegawa, J.-C. He, M. Fujiwara, S. Nogami, M. Satou, T. Shishido, K. Abe, Materials Transactions 48 (2007) 2399.

[65] T. Tanno, A. Hasegawa, M. Fujiwara, J.-C. He, S. Nogami, M. Satou, T. Shishido, K. Abe, Materials Transactions 49 (2008) 2259.

[66] T. Tanno, M. Fukuda, S. Nogami, A. Hasegawa, Materials Transactions 52 (2011) 1447.

[67]A.Hasegawa, M.Fukuda, T.Tanno, S.Nogami, will be presented in this conference(ICFRM-15)

[68] A. Hasegawa, T. Tanno, S. Nogami, M. Satou, Journal of Nuclear Materials 417 (2011) 491.

[69]M.Fukuda, A. Hasegawa, T. Tanno, S. Nogami, „Property change of advanced tungsten alloys due to neutron irradiation“, will be presented in this conference(ICFRM-15)

[70] Q. Xu, N. Yoshida, T. Yoshiie, Journal of Nuclear Materials 367-370 A (2007) 806.

[71] T. Crosby, N.M. Ghoniem, Interaction and Multiscale Mechanics 4 (2011) 207.

[72] B. Gludovatz, S. Wurster, T. Weingartner, A. Hoffmann, R. Pippan, Philosophical Magazine 91 (2011) 3006.

[73]G. D. Samolyuk, Y. N. Osetskiy, and R. E. Stoller, Semiannual Report of Fusion Reactor Materials Program 49, 90 (2010)

[74] W. Setyawan, R.J. Kurtz, Scripta Materialia 66 (2012) 558.

[75] D. Wolf, S. Yip, Materials Interfaces: Atomic-level structure and properties, The University Press, Cambridge, 1992.

[76] G.J. Ackland, R. Thetford, Philosophical Magazine A 56 (1987) 15.

[77] G. Kresse, J. Hafner, Physical Review B 47 (1993) 558. 
[78] G. Kresse, J. Furthmüller, Physical Review B - Condensed Matter and Materials Physics 54 (1996) 11169.

[79] P.E. Blöchl, Physical Review B 50 (1994) 17953.

[80] G. Kresse, D. Joubert, Physical Review B - Condensed Matter and Materials Physics 59 (1999) 1758.

[81] J.P. Perdew, K. Burke, M. Ernzerhof, Physical Review Letters 77 (1996) 3865.

[82] W. Setyawan, S. Curtarolo, Computational Materials Science 49 (2010) 299. 